\title{
Harmful chemicals emitted from electronic cigarettes and potential deleterious effects in the oral cavity
}

\author{
Jeffrey Ebersole', Vera Samburova², Yeongkwon Son², David Cappelli', Christina Demopoulos' ${ }^{1}$ Antonina Capurro', \\ Andres Pinto ${ }^{3}$, Brian Chrzan ${ }^{1}$, Karl Kingsley', Katherine Howard ${ }^{1}$, Nathaniel Clark' , Andrey Khlystov ${ }^{1}$
}

\begin{abstract}
Use of electronic nicotine delivery systems (ENDS), such as electronic cigarettes (e-cigs), is increasing across the US population and is particularly troubling due to their adoption by adolescents, teens, and young adults. The industry's marketing approach for these instruments of addiction has been to promote them as a safer alternative to tobacco, a behavioral choice supporting smoking cessation, and as the 'cool' appearance of vaping with flavored products (e.g. tutti frutti, bubble gum, and buttered popcorn etc.). Thus, there is a clear need to better document the health outcomes of e-cig use in the oral cavity of the addicted chronic user. There appears to be an array of environmental toxins in the vapors, including reactive aldehydes and carbonyls resulting from the heating elements action on fluid components, as well as from the composition of chemical flavoring agents. The chemistry of these systems shows that the released vapors from the e-cigs frequently contain levels of environmental toxins that considerably exceed federal occupational exposure limits. Additionally, the toxicants in the vapors appear to be retained in the host fluids/tissues at levels often approximating $90 \%$ of the levels in the e-cig vapors. These water-soluble reactive toxins can challenge the oral cavity constituents, potentially contributing to alterations in the autochthonous microbiome and host cells critical for maintaining oral homeostasis. This review updates the existing chemistry/environmental aspects of e-cigs, as well as providing an overview of the somewhat limited data on potential oral health effects that could occur across the lifetime of daily e-cig users.
\end{abstract}

AFFILIATION
1 Department of Biomedical
Sciences, School of Dental
Medicine, University of Nevada Las
Vegas, Las Vegas, United States
2 Organic Analytical Laboratory,
Division of Atmospheric Sciences,
Desert Research Institute, Reno,
United States
3 Oral and Maxillofacial Medicine
and Diagnostic Sciences, School
of Dental Medicine, Case Western
University, Cleveland, United States
CORRESPONDENCE T0
Jeffrey Ebersole. Department of
Biomedical Sciences,
School of Dental Medicine, B221
University of Nevada Las Vegas, Las
Vegas, NV 89106, United States.
E-mail: jeffrey.ebersole@unlv.edu
ORCID ID: https://orcid.org/0000-
0002-9743-6585

KEYWORDS

electronic nicotine delivery systems, e-cigarette, vaping, oral health, public health

Received: 1 November 2019 Revised: 20 November 2019 Accepted: 22 January 2020

\section{INTRODUCTION}

Tobacco use has decreased nationally over the last decades; however, electronic cigarette (e-cigs or electronic nicotine delivery system, ENDS) use is dramatically increasing in the US, especially among adolescents, teens and young adults where it has risen sharply since $2011^{1,2}$. E-cigs are handheld devices that produce an aerosolized mixture from a solution (i.e. e-liquid) typically containing nicotine, flavoring chemicals, vegetable glycerin (VG), and propylene glycol (PG), to be inhaled by the user ${ }^{3}$. The addictive nature of the e-cigs can be attributed to the nicotine levels in the device and the flavoring of the chemicals that target youth and young adults. Data from the 2011-2018 National Youth Tobacco Survey (NYTS) determined that current usage of e-cigs among high school students has risen from $1.5 \%$ in 2011 to $20.8 \%$ in 2018 - a more than 13-fold increase. According to a 2013-2014 survey of adults and youth, flavored tobacco products predominantly attract young users (aged 12-24 years) and $81 \%$ of youth that currently use e-cigs cited appealing flavors as a primary reason 
for first using a tobacco product ${ }^{4}$. Research has shown that adolescents are more likely to experiment with substances such as cigarettes, and they are physically more vulnerable to addiction ${ }^{5}$. There are mixed views regarding the safety and efficacy of e-cigs, even among healthcare professionals. While some individuals view e-cigarettes as a public health concern, others recommend them as a safer alternative to conventional cigarettes for smokers who are unwilling/unable to quit. With the advent of new delivery systems and the addictive nature of nicotine, one can see how e-cigs can negatively impact the health of youth and young adults with potential for long-term impacts on oral health over a lifetime. However, the relative recent e-cig epidemic has not yet provided robust datasets to assess if systemic diseases result from the long-term usage of e-cigs. Regardless of the current debate on the use of e-cigs as an effective smoking cessation aid, the dramatic increase in e-cig usage among never smokers demands a clear need to better document the health outcomes of e-cigs in the oral cavity of the addicted chronic user.

There appears to be an array of environmental toxins in the vapors, including reactive aldehydes and carbonyls resulting from the heating elements action on fluid components, as well as from the composition of chemical flavoring agents. These reactive toxicants can challenge the oral cavity constituents, potentially contributing to alterations in the autochthonous microbiome and host cells critical for maintaining oral homeostasis. This review updates the existing chemistry/environmental aspects of e-cigs, as well as providing an overview of the somewhat limited data regarding potential oral health effects that could occur over the lifetime of daily e-cig users.

\section{DEVELOPMENTS}

\section{Toxic/noxious end-products in e-cig vapors}

As stated in the Surgeon General's Report, E-Cigarette Use Among Youth and Young Adults, e-cigs contain varying levels of nicotine and other chemicals known to increase the risk of cancer $^{6}$. According to Goniewicz et al. ${ }^{7}$, carcinogens, such as formaldehyde, acetaldehyde, and nitrosamines have been found in e-cig vapor. In addition, diacetyl is added to e-cigs, which destroys the airways in the lungs and can cause popcorn lung or bronchiolitis obliterans ${ }^{8}$. Findings suggest that e-cigs not only have systemic health concerns, but can also negatively affect the oral cavity. The chemical vapors produced by vaping can alter or damage the epithelial cells, leading to oral ulcerations or oral cancer ${ }^{9}$.

Toxic compounds, such as heavy metals, carbonyls, flavoring chemicals, and reactive oxygen species (ROS), have been detected in e-cig aerosols in concentrations that can adversely affect oral health (Figure 1). Some of these toxic compounds, such as diacetyl, can be found in some e-liquids, while others such as metals, carbonyls, and ROS, can form during e-cig use. During the vaping process, e-liquid is vaporized by a heating element operating at temperatures ranging between 100 and $300^{\circ} \mathrm{C}$ depending on the e-cig construction and power output. High temperatures facilitate transfer of heavy metals (e.g. nickel, cadmium, chromium, and lead) from the coil into the e-liquid ${ }^{10}$. E-liquid impurities and break-down of wick material may also lead to the presence of toxic elements such as arsenic and silica in e-liquids ${ }^{11}$. Aerosolization of e-liquid leads to emissions of these substances during vaping. A higher e-cig power output as well as aging of heating element wires could increase metal emissions ${ }^{12}$. Exposure to these metals is of concern as it can cause chronic periodontitis, oral cancer, inflammation, and neurodegeneration ${ }^{11}$.

E-cigs are also known to emit amounts of carbonyls (i.e. formaldehyde, acetaldehyde, acrolein, etc.) that depend on e-cig vaping conditions, such as vaping topography, power output, device construction, coil material, and e-liquid components. E-cig vaping topography, which refers to puff duration and volume, can affect processes occurring on the coil surface. A longer puff duration increases formation of toxic carbonyls under the same puff volume ${ }^{13}$. The same e-cig device produces significantly more carbonyls at a higher power setting due to the higher thermal decomposition rate of e-liquid components including $\mathrm{PG}, \mathrm{VG}$, and flavoring chemicals ${ }^{14,15}$. However, a better predictor of carbonyl emission strength is the ratio of applied power to the coil surface area: e-cigs with larger coils tend to produce less carbonyls per unit power output ${ }^{16}$. E-liquid composition also affects carbonyl emissions. At a fixed e-cig power output, PG-based e-liquids form more toxic carbonyls than VG-based e-liquids ${ }^{17}$. However, the main part of carbonyl compounds is due to the 
Figure 1. E-cig processes that contribute to potential toxicity for oral tissues

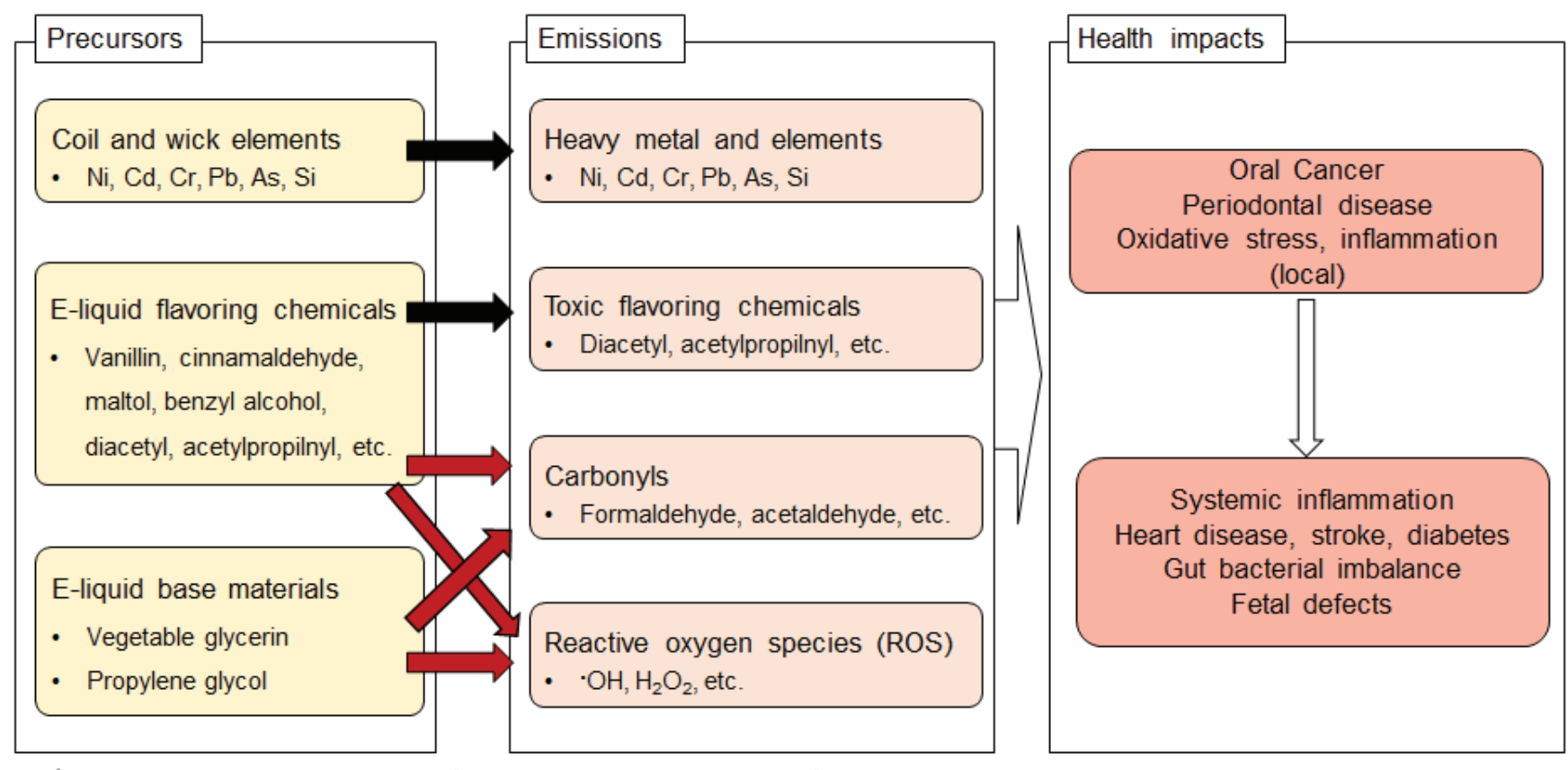

Aerosolization/evaporation $\Rightarrow$ Thermal decomposition $\Rightarrow$ Health impacts

thermal decomposition of flavoring compounds $\mathrm{s}^{18,19}$ or flavor-catalyzed decomposition of $\mathrm{PG}^{20}$. Carbonyl emissions also depend on the coil material, as metals in the e-cig heating element have been shown to accelerate thermal decomposition of e-liquid organic components triggering the formation of toxic carbonyl compounds ${ }^{21}$.

Formaldehyde levels in e-cig aerosols were reported to significantly exceed the occupational safety limits ${ }^{10,15,18,22-24}$. It has been debated that high carbonyl concentrations do not occur during normal e-cig usage and are generated only under so-called 'dry-puff' conditions that e-cig users avoid ${ }^{25}$. 'Drypuffs' occur due to insufficient e-liquid supply to the wick leading to overheating of the liquid, resulting in a significant increase in toxic carbonyl emissions. However, a recent study noted high levels of toxic carbonyls in exhaled e-cig aerosols during normal e-cig usage ${ }^{26}$. Formation of ROS in e-cigs was also reported to depend on the kind of flavoring chemicals present in e-liquids ${ }^{27,28}$. Similar to carbonyl emissions, higher power outputs and longer puffs generate more hydroxyl radicals, the most destructive ROS species that can damage DNA, proteins, and lipids ${ }^{28}$. A VGbased e-liquid was reported to produce more hydroxyl radicals than a PG-based one ${ }^{29}$.

Toxic flavoring chemicals that cause 'popcorn lung' disease, diacetyl and acetylpropionyl, were detected in some milk-, butter-, fruit-, candy-, and cocktailflavored e-liquids ${ }^{30}$. Sweet, chocolate, and cinnamon flavoring chemicals in e-liquids showed cytotoxic effects, oxidative stress, and inflammation responses in several in vitro studies ${ }^{31-33}$. In vitro toxicological e-cig studies are complicated due to the highly volatile and concentrated nature of e-cig aerosols and the difficulty to adequately capture the wide range of e-cig use patterns. Previous e-cig toxicological studies used smoking machines designed for conventional cigarettes and fixed vaping condition ${ }^{33-35}$. The exposure protocols in those studies were shown to be suboptimal because they alter e-cig aerosols and are unable to reproduce the wide range of e-cig vaping conditions. To overcome these limitations, an e-cig vaping machine was designed and used to generate e-cig aerosols at various vaping topography parameters to standardize the exposure protocol and achieve reproducible exposure results ${ }^{36}$. In another in vitro study, epithelial cells were exposed to undiluted fresh e-vapor using a 3D culture system ${ }^{28}$. This direct exposure system could maintain physical and chemical 
integrity of e-cig aerosol, mimicking the real-world exposure condition. Even though advances in e-cig toxicological study protocols have been made in recent years, local dosimetry of e-cig emissions needs to be studied further to identify local impact such as those on oral health.

In addition to in vitro studies, in vivo e-cig exposure studies are desired. A recent pilot study reported carbonyl retentions in e-cig users during e-cig vaping ${ }^{26}$. In 14 out of 19 cases, carbonyl levels in exhaled e-cig aerosols were 2-125 times higher than in pre-exposed breath. A significant fraction, $99.7 \pm 0.9 \%$ and $91.6 \pm 10 \%$ of carcinogenic formaldehydes and acetaldehydes, respectively, was retained by the users. High water solubility and reactivity of formaldehydes and acetaldehydes were shown to facilitate oronasal deposition of inhaled toxic carbonyls ${ }^{37}$. The high oronasal retention of formaldehydes and acetaldehydes could worsen oral health. There have been no reports yet on how inhaled e-cig formaldehydes and other toxic aldehydes are associated with oral diseases.

\section{E-cig use and oral health/disease}

Studies of e-cig use continue to dissect out clinical impacts that include knowledge from animal models and cell biology studies to formulate an estimate of the magnitude of deleterious health consequences of e-cig use. While oral cancer outcomes of conventional cigarettes are well known, the role of e-cig use in this process has not been fully elucidated. With the increasing use of e-cigs, particularly in younger people, the long-term impact of this addictive behavior must be part of the repertoire of knowledge and actions of dental and oral health providers within the overall healthcare team ${ }^{38}$. Aldehyde adducts in tobacco smoke are clearly major factors in DNA damage and decreased repair, while acrolein also reduces DNA and protein repair processes ${ }^{39}$. E-cig aerosols induce DNA damage and decrease cellular antioxidant defences independent of nicotine on oral and lung epithelial cells ${ }^{40}$. Canistro et al..$^{41}$ demonstrated the co-mutagenic and cancer-initiating effects of e-cig vapor in a rat lung model. Nicotine from e-cigs negatively impacted cell viability and proliferation of both cancerous and non-cancerous cells ${ }^{42}$. The role of e-cig derived nicotine on cellular functions including profibrotic response and other functional aspects is not known ${ }^{43}$. Thus, the knowledge base in this area still lacks robust data on the effect of vaping on the gingiva, and an evidence-base needs to be established $^{44}$.

\section{Cell biology}

Although much remains to be discovered regarding the effects of various additives and by-products of e-cig vapors, a growing body of evidence has demonstrated cytotoxicity in the most likely affected cell types ${ }^{45,46}$. Acrolein, the simplest unsaturated aldehyde, has been demonstrated to be highly reactive, functions to cross-link DNA, and may be sufficient in e-cig vapors at concentrations that inhibit cytochrome P450 enzymes and induce apoptosis in a variety of lung and bronchial cells ${ }^{47,48}$. In addition, more recent evidence has suggested that reactive aldehydes, including acrolein, may induce ion channel dysfunction by reducing chlorine transport in airway epithelia $^{49,50}$. Other cell types that may be affected by aldehydes, including formaldehyde and acrolein, include long basal epithelial cells, which acquired DNA strand breaks and other chromosomal damage at sub-cytotoxic concentrations, supporting observations of in vitro models ${ }^{51-53}$.

Further research supports these observations that reactive carbonyl species, such as the a and $\beta$-unsaturated aldehydes induce oxidative stress and increased protein carbonylation, which contributes to cardiovascular, pulmonary and oral cavity diseases and dysfunction ${ }^{54,55}$. Also, bronchial epithelial cells exhibit impaired ciliary function and cellular function in response to these e-cig components, which may be more pronounced when present in combination with nicotine ${ }^{56,57}$. However, the adverse cellular responses to e-cig aerosols are not limited to normal, healthy tissues but may also function to promote proliferation and transition to cancer in some tissue types ${ }^{58-60}$. Recent comparisons of e-cig users demonstrate elevated levels of carcinogens compared with controls, as well as the potentially higher risk of transformation of premalignant lesions and development of oral and esophageal cancers $^{61,62}$. For example, e-cig consumers exhibit changes to oral mucosal lesions that may be comparable to those of smokers, and the effects of oxidative damage and other deleterious effects may exhibit more profound effects in premalignant and malignant lesions than in normal, non-cancerous tissues ${ }^{40,63}$. 
More specifically related to reported effects on the oral cavity, e-liquid constituents increased cytotoxicity and apoptosis in human gingival fibroblasts, not related to nicotine content ${ }^{64}$. These types of e-liquids with or without nicotine also demonstrated cytotoxic and genotoxic effects on human oropharyngeal mucosa $a^{65}$ and showed varied effects on epithelial cell proliferation and viability that extended beyond the constituents of nicotine and propylene glycol/ vegetable glycerin in the e-liquid fluids ${ }^{66}$. E-cig aerosols, likewise, reduced the viability and increased apoptosis and necrosis of epithelial cells unrelated to nicotine content ${ }^{67}$, as well as causing increased oxidative/carbonyl stress, inflammatory cytokines, DNA damage, and reduced HDAC2 responses in fibroblasts and gingival epithelium ${ }^{9}$. E-cig aerosols significantly decreased glutathione levels in oral keratinocytes leading to increased cytotoxicity ${ }^{68}$, and induced ROS, DNA damage and toxicity for vascular endothelial cells ${ }^{69}$, apparently reflecting changes in oxidative stress by components in these aerosols.

Beyond the potential direct effects on the critical epithelial barrier at mucosal surfaces, including the oral cavity, expanding literature has identified negative outcomes for e-cig vapor components on cells of the immune system. Cinnamaldehyde-containing e-cig liquids are broadly immunosuppressive for multiple immune cell types ${ }^{50}$. E-cig aerosol condensate was toxic to alveolar macrophages and increased ROS and inflammatory cytokines and chemokines, thus contributing to the inflammatory milieu in the lungs ${ }^{70}$. E-cig aerosols also increase pro-inflammatory cytokine production in models of human airways and decrease cell viability apparently unrelated to apoptotic processes ${ }^{71}$.

Thus, a combination of these deleterious outcomes driven by e-liquids and e-cig aerosols would be expected to demonstrate adverse effects on the health of the oral cavity. This concept continues to be supported by expanding literature in this field.

\section{Periodontal disease}

\section{$\underline{\text { Microbiome }}$}

In humans, the interaction between animal and bacterial cells is especially important at mucosal surfaces. Methodologic advances have enabled rapid progress in characterizing the taxonomic composition, metabolic capacity, and immunomodulatory activity of the human microbiome, enabling insights into its role in health and disease. Yanushevich et al. ${ }^{72}$ suggested a consideration of 'pathological colonization level' as a concept that could be explored to better assess the complex etiologic factors in periodontitis. Defining the characteristics of the oral microbial ecology in periodontitis has also required the incorporation of various confounders, including age ${ }^{73}$, diabetes ${ }^{74}$, rheumatoid arthritis $^{75}$, inflammatory bowel disease ${ }^{76}$ and $\operatorname{sex}^{77}$ as potentially modifying the oral microbiome in health and disease. However, no extrinsic modifier appears to have a greater effect on periodontal disease prevalence and severity than tobacco smoking ${ }^{78}$. While underlying critical triggers are unknown, current concepts of the transition of the ecology from health to disease now emphasize an altered balance of the oral microbiome, resulting in a 'dysbiosis"79 (Figure 2). It still remains ill-defined how this dysbiosis is created and whether this is primarily being driven by an emergence of pathogenic bacteria in the subgingival ecology and/or stimulation of a dysregulated host innate and inflammatory response that is modulated by genetic and epigenetic predisposition, as well as patient-modifiable factors including smoking, diet, diabetes, stress etc. ${ }^{79}$ In this regard, little current information is available on the impact of e-cigs in altering the oral microbiome to increase disease risk. Thus, the stage has been set with years of investigation and dramatic improvements in technologies to better understand the array and organization of a homeostatic microbiome so as to delineate critical changes that might occur that are driven by the use of e-cigs.

\section{Mucosal responses}

Mucosal tissues are colonized by an extremely dense and diverse microbiota of commensal bacteria, and are often the first sites of interaction with pathogenic microorganisms ${ }^{80,81}$. The first line of defence is sentinel cells consisting of macrophages, dendritic cells (DCs), and granulocytes patrolling for evidence of microbial challenge or infection. These cells effectively engage microbes using a repertoire of pattern recognition receptors (PRRs) ${ }^{82}$, which recognize distinct classes of microorganism-associated molecular patterns (MAMPs), including a range of bacterial, viral, and fungal pathogen ligands ${ }^{83}$.

Recent evidence has emphasized the plasticity of 
Figure 2. Schematic of the current paradigm in the microbiome of periodontitis, with a normal homeostatic microbiome comprising a large array of species of bacteria, which is symbiotic with host tissues and host responses

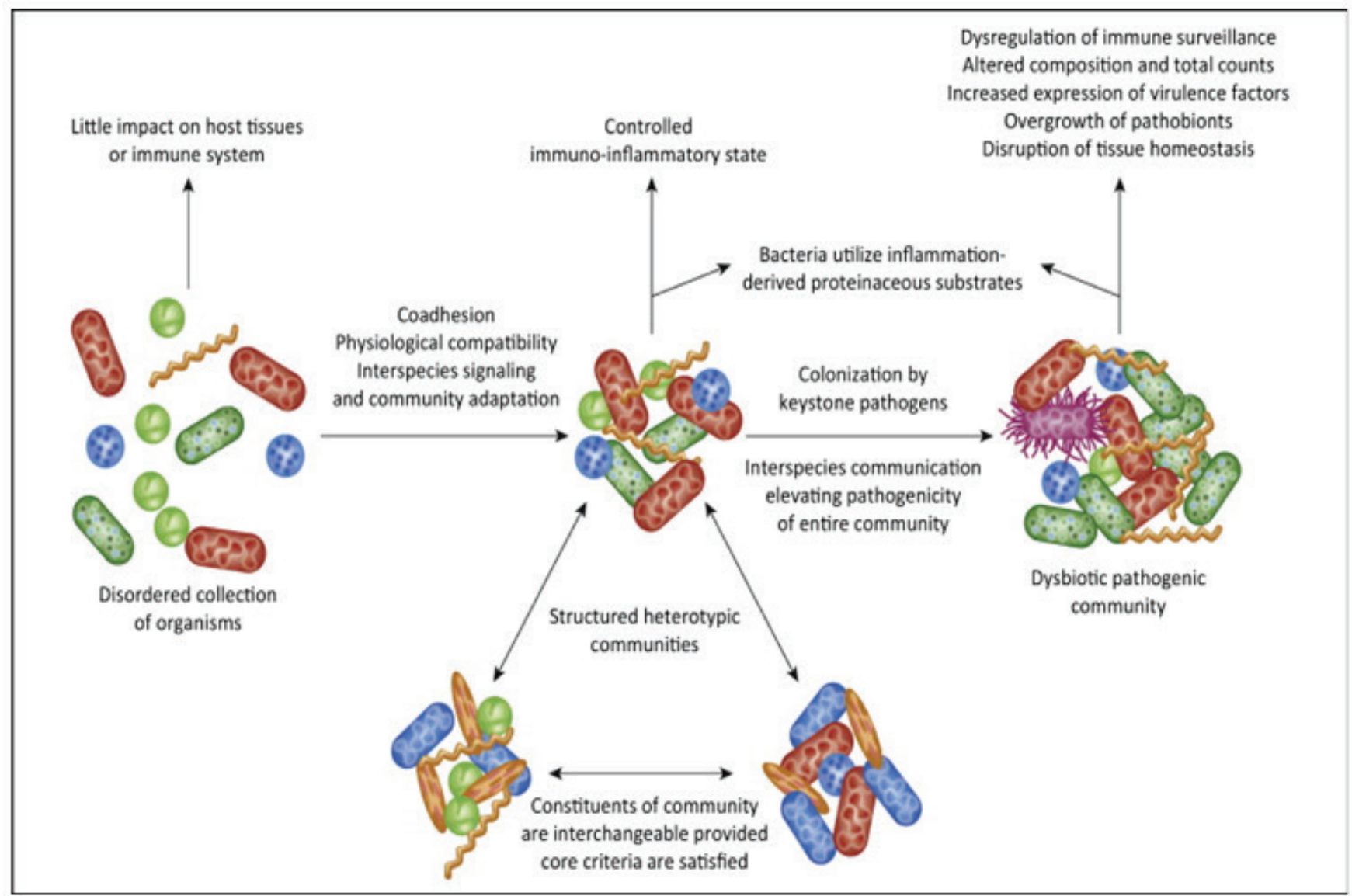

Increases in the microbiome, and in particular certain constituent members, result in an immunoinflammatory response that is appropriately regulated and can control the effects of the microbiome, thus limiting any tissue destructive events. The emergence of a 'keystone pathogen' such as P. gingivalis, which responds effectively to local subgingival environmental changes, contributes to dysregulating the host responses, allowing overgrowth of pathobionts, altering gene expression and metabolic functions of commensal bacteria, and disrupting tissue homeostasis resulting in a disease process (adapted from [128]).

numerous immune cell types related to protection from infection, regulation of phenotypes and functions of inflammatory and immune responses, and development of tumors (Figure 3 ). These variations are regulated by the types of microorganisms providing the stimulus and the local host microenvironment ${ }^{84}$. The resulting signaling pathways activated through these receptors and processes lead to different immune cell response patterns, including macrophages, dendritic cell subsets, neutrophil subpopulations, seven different CD4+ T cell subsets, and B-lymphocyte heterogeneity.

A summary of existing reports demonstrates that this array of phenotypes of immune cells are present in the periodontium, respond to the environment at diseased sites, and likely contribute crucial functions to maintaining or re-establishing homeostasis of the oral tissues. The regulatory processes needed for homeostasis and dysregulation of these cell types with disease is of particular importance at mucosal surfaces as they are in constant association with external antigenic stimuli including pathogenic biofilms. Thus, the profile of cellular plasticity variations related to health or disease remains to be determined; however, studies exploring the role of plasticity in the pathogenesis of chronic inflammatory diseases and the potential altered cell repertoire elicited by stressors, such as those contained in e-cig products, are clearly needed.

\section{E-cig (ENDS) effects}

The literature remains less than robust regarding long-term e-cig usage and effects on oral health. However, clear data on conventional cigarette use, 
Figure 3. Immune system plasticity

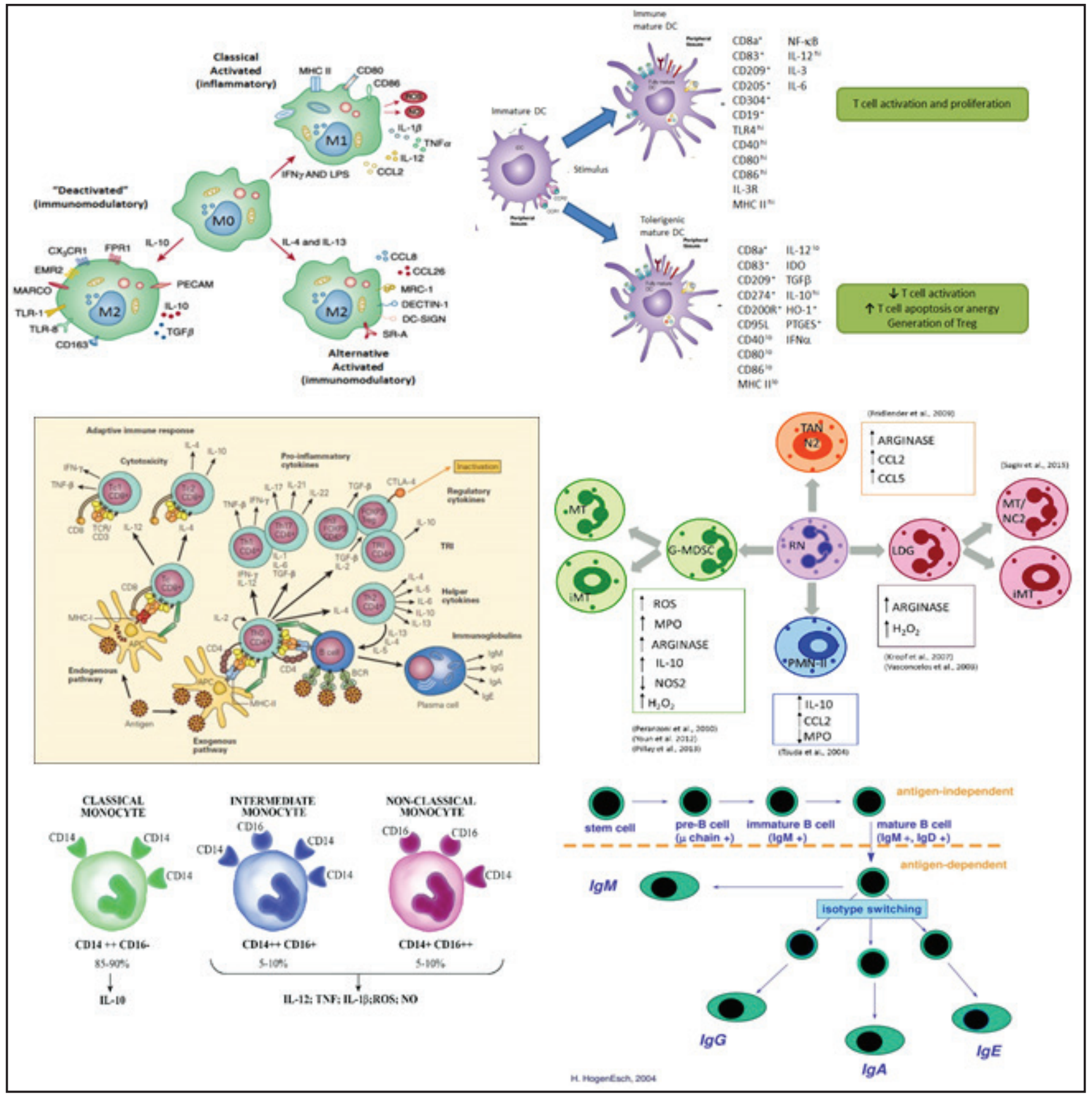

Plasticity and polarization of macrophage functions related to host and microbial stimuli (adapted from [129]). General overview of characteristics of DC phenotypes with different functional activities in innate and adaptive immunity (adapted from [130]). Schematic representation of the two major pathways of T cell differentiation: Th and Tc populations and their subsets (adapted from https://www.immunopaedia.org.za/immunology/basics/5-overview-of-t-cell-subsets/). Most well-described regulatory neutrophil (RN) subtypes and their main mechanisms of action. TAN-N2 (Tumor associated neutrophil type 2); G-MDSC (Granulocytic myeloid derived suppressor cell); PMN-II (Polymorphonuclear type II); LDG (low-density granulocyte); NC2 (circulating neutrophils type 2); MT (mature); and iMT (immature) (adapted from https://www.intechopen. com/books/role-of-neutrophils-in-disease-pathogenesis/neutrophils-plasticity-the-regulatory-interface-in-various-pathological-conditions). Human circulating monocyte subsets. Human blood monocytes can be separated into three subsets according to the CD16 and CD14 expression: classical monocytes (CD14 ${ }^{++}$CD16-), which represent the majority of circulating monocytes, produce the anti-inflammatory IL-10 upon stimulation; intermediate monocytes (CD $\left.14^{++} \mathrm{CD} 16^{+}\right)$; and non-classical monocytes (CD14 $\left.4^{+} \mathrm{CD} 16^{++}\right)$ which secrete inflammatory cytokines such as IL-1 $\beta, I L-12$, TNF, and antimicrobial molecules [nitric oxide (NO) and reactive oxygen species (ROS)] (adapted from [131]). B cell development and plasticity.

and also on waterpipe tobacco use, which is becoming increasingly popular with younger people, associated with periodontitis, premalignant oral lesions, and oral and esophageal cancers, are lacking ${ }^{62}$. Clinical oral data with e-cig use are not clear. Periodontal inflammation was found to be decreased in cigarette 
and e-cig users compared to non-smokers, and selfperceived oral symptoms were worse in cigarette smokers than in e-cig users ${ }^{85}$. Similarly, following full mouth ultrasonic scaling, gingival inflammation was found to be elevated in cigarette smokers compared to e-cig users and non-smokers ${ }^{86}$. Moreover, other reports suggest that clinical measures of periodontal disease are no different in e-cig versus never smokers and greater in tobacco smokers. Similar results were found with salivary levels of some inflammatory mediators ${ }^{87}$. E-cigs vaporize a mixture of PG/VG, nicotine and flavoring agents with some marketing focus as an aid in smoking cessation with limited data of self-report and oral exams suggesting some improvement over tobacco smoking ${ }^{88}$.

However, other investigations have indicated that pathophysiological changes occur with e-cig aerosols including oxidative stress, DNA damage, altered innate host responses, inflammation, cellular senescence, profibrinogenic and dysregulated repair that could contribute to oral disease including periodontitis ${ }^{85}$. Formaldehyde toxicity also was reported to disrupt the functions of the periodontium, including alveolar bone, and altered cell growth and remodeling factors in rats ${ }^{89}$. Finally, elevated levels of proinflammatory cytokines are detected in crevicular fluid of dental implants in cigarette and e-cig users ${ }^{90}$.

\section{Orthodontic complications}

Orthodontic tooth movement has been well characterized related to the induced inflammatory response that focuses activation of osteoblasts or osteoclasts resulting in differential bone formation and resorption, enabling the tooth to move. Various more recent approaches have attempted to utilize knowledge of the biology of these processes to enhance the capability for more rapid and reproducible movement. However, within the context of the mechanical aspects of this treatment, multiple 'confounders' can affect the quality of the outcome. Within the oral microbiome, there are differences that occur in the quantity and quality of the microbial members related to the bonding of brackets to the teeth, or even with the more recent adoption of the clear aligner treatment technology. These microbiome changes have been associated with both white spot and risk of carious lesions, as well as an accretion of bacteria that can trigger untoward inflammatory responses. Thus, another component is the regulation or dysregulation of inflammatory responses that are necessary for tooth movement, but may pose a risk for eliciting periodontitis. Finally, there are clear data regarding an increased incidence of external apical root resorption (EARR) that likely has both genetic and environmental contributors ${ }^{91}$.

Although there are no studies that have evaluated the complex mixture of e-vapors and orthodontic tooth movement, available studies related to this topic are those that have examined the effect of nicotine alone on bone resorption related to orthodontic tooth movement. Several of these studies have demonstrated that nicotine administration increases the rate of orthodontic tooth movement in a dosedependent manner ${ }^{92-95}$. Accelerated tooth movement is often considered desirable in orthodontic treatment; however, the application of orthodontic force with exposure to nicotine causes a significant increase in periodontal bone loss compared to orthodontic force alone ${ }^{96}$.

\section{Microbiome}

Various oral bacterial, including uncommon species, and fungal species are increased significantly after application of fixed/removable orthodontic appliances ${ }^{97-100}$. Greater microbial diversity was noted in patients with orthodontic appliances by 10-12 months, accompanying some differences in species distribution between the controls and orthodontic treatment ${ }^{101}$, although some decreases in the microbiome diversity were observed in clear aligners ${ }^{102}$. Finally, following fixed orthodontic bracket removal, decreases in several oral pathogens were observed and were related to gingival bleeding and plaque levels ${ }^{103}$. A broad array of bacterial taxa was identified with white spot lesions (WSL), as well as with gingivitis in children with fixed appliances. Adjustment for gingivitis did not alter the taxa associated with WSL, and certain taxa were more strongly related to gingivitis ${ }^{104}$. C. albicans was also increased in saliva and plaque samples in patients with white spot lesions formed during multi-bracket orthodontic appliance treatment ${ }^{105}$. Furthermore, recent systematic reviews supported increases in $S$. mutans and Lactobacillus spp., as well as potentially pathogenic Gram-negative oral species following orthodontic appliances ${ }^{106}$. Additionally, selected oral 
periodontal pathogens were elevated after appliance placement with levels decreasing a few months postremoval of the brackets ${ }^{107}$.

While virtually no data are available regarding e-cig use and microbiomes with orthodontic therapy, as the increased usage of e-cigs overlaps with the patient age range seeking orthodontic treatment, based on existing literature of e-cigarette effects on the oral microbiome, one must ask clinical questions regarding the potential longer-term deleterious consequences of vaping on successful orthodontic therapy.

\section{Inflammation}

Regarding the details of gingival inflammation related to orthodontic tooth movement that could be affected by the use of e-cigs, increased plaque levels were noted after bracket bonding and major increases in gingivitis measures were routinely observed ${ }^{100}$. Within three months of bracket placement, bleeding on probing, plaque index and gingival index were significantly increased, with multiple putative periodontal pathogens elevated and related to the increased inflammation ${ }^{97}$. In contrast, rather minimal increases in plaque and gingival bleeding were noted in patient's after clear-aligner placement ${ }^{102}$. Several cell types responsible for the maintenance of alveolar bone and orthodontic tooth movement are adversely affected by exposure to nicotine. In vitro studies using PDL fibroblasts have demonstrated increased expression of COX-2, PGE2, IL-6 and RANKL with a simultaneous decrease in osteoprotegerin (OPG) expression during nicotine exposure.

Beyond these rather limited observations, the breadth of the population accessing orthodontic tooth movement and the increasing number of individuals addicted to e-cigs might be anticipated to result in an increased prevalence of adverse outcomes of the orthodontic treatment in this subset of the population.

\section{Bone biology}

The balance between bone formation on the tension side and resorption on the compression side of a moving tooth is critical to achieving net movement when orthodontic forces are applied. Nicotine disrupts this balance by suppressing osteoblast proliferation and inducing osteoblast apoptosis resulting in an overall decrease in osteoblastic activity on the tension side of teeth subjected to orthodontic forces ${ }^{93,108-110}$.
This imbalance results in increased alveolar bone resorption around moving teeth and acceleration of tooth movement ${ }^{95}$. The increases in osteoclastogenic differentiation of osteoclast precursors and resorption activity of mature osteoclasts by nicotine appear to be mediated by changes in RANKL-RANK signaling and the expression of TNFa and $\mathrm{PGE}_{2}{ }^{111}$.

Orthodontically-induced inflammatory root resorption (OIRR) is also an undesirable effect observed with accelerated orthodontic tooth movement due to the administration of nicotine ${ }^{94}$. Using an in vivo rat model, significantly more root resorption was observed with increased odontoclastogenesis and expression of RANKL with nicotine exposure ${ }^{112}$. Considering that RANK/RANKL signaling regulates both bone resorption by osteoclasts and root resorption by odontoclasts, it is not surprising that both are affected by nicotine exposure. Finally, a recent report mentioned that e-liquids can lead to osteotoxicity, primarily via effects on osteoblasts. The effects were flavor-dependent and independent of nicotine ${ }^{113}$.

The inflammatory changes and bone altering biomolecules associated with nicotine in e-cig vapor would result in increases in OIRR and periodontal bone loss, compromising the oral health of patients and stability of the final orthodontic result. The associated risks of nicotine and e-cigs should be discussed with prospective orthodontic patients and treatment should be delayed until the patient has ceased all nicotine consumption.

\section{Other Oral Conditions}

\section{Oral lesions}

The occurrence of oral mucosal lesions in e-cig users was compared to previous smokers in a small sample recruited over two years ${ }^{63}$. The overall prevalence of oral mucosal lesions was $61 \%(n=55)$. Forty-five per cent of these were fungal infections, with 16 cases reported in the e-cig group. There was no significant difference between the two groups in terms of the frequency of lesions. Of interest, the presence of hyperplastic candidiasis on the commissure area in the e-cig users in this study was hypothesized to be associated with the process of heat vaporization and non-nicotine elements released into the perioral area. Other commonly reported lesions in the study for e-cigs were nicotinic stomatitis and hairy tongue. In vitro evidence describes increased pathogenicity 
of Candida albicans when exposed to commercial e-vapor ${ }^{114}$. This effect was mediated by an increased expression of chitin and secretory aspartate proteases (SAP2, 3 and 9) and phenotypic changes such as increased hyphal length. Direct comparison with nonexposed C. albicans cultures not exposed to the vapor highlighted significant interactions and enhanced adhesion of the fungus to gingival cells. This report enforces the still preliminary, yet substantive evidence, about a higher risk of fungal infection in e-cig users versus traditional smokers.

Aldehydes found in components of e-cigs are also linked to a higher risk of autoimmune reactions ${ }^{115}$. A murine model demonstrated an increase in autoimmune markers in mice exposed to perchloroethylene in the water at 12,18 and 24 weeks, including levels of serum ANA (anti-nuclear antibodies), dsDNA (double-stranded DNA) and Scl-70 (scleroderma) antibodies. This increase was time-dependent and accompanied by a decrease in antioxidants mediated by lipid-derived aldehydes. The potential for autoimmune changes may influence the future occurrence of oral lesions with expanded long-term usage of e-cigs.

\section{Mucosal pain}

Perhaps one of the most intriguing areas in regard to adverse effects of e-cigs is mucosal irritation/pain. A population-based survey of high school students conducted in Korea explored the prevalence of gingival, tongue, and buccal mucosa pain in users of e-cigs versus controls ${ }^{116}$. Among 33309 responders, e-cig users were at a $54 \%$ higher risk of developing tongue and buccal mucosa pain. Additional evidence on the effect of nicotine and the possible effect of aldehydes (cinnamaldehyde) on pain receptors has been reported in controlled human studies ${ }^{117}$. Nicotine functions as an activator of the transient receptor potential subtype A1 (TRPA1) channel, associated with oral burning. This preliminary study reported subjects sensitized to the aldehyde reporting more burning complaints when exposed to nicotine. Both cinnamaldehyde and nicotine also alter the vasomotor activity in the oral and pharyngeal mucosa, and chronic exposure may modify pain reception in these areas ${ }^{118}$. To our knowledge, no publication has addressed this effect in e-cig users. With variability in nicotine content of e-cigs, the impact on oral pain perception may be higher than cigarette users. Another study reported no significant differences in gingival pain (as a secondary outcome) between e-cig users and controls. This study used a convenience sample and reported periodontal measures as the primary outcome ${ }^{119}$.

This physiological underpinning may support the phenotype of burning mouth syndrome, an oral pain disorder associated with several neuropathic diseases, and possibly hematinic or endocrine deficiencies. Some cases, particularly those only involving the tongue in the presence of marginal salivary flow, may be related to the effect of nicotine on specific pain receptors in smokers. Several studies identify cigarette smoking as an independent factor associated with this condition ${ }^{120}$.

\section{Drug-induced hyposalivation}

The primary efficacy of e-cigs on the reduction of craving was demonstrated in several recent systematic reviews ${ }^{121}$. As previously stated, many of these effects are mostly unknown and possibly related not only to nicotine but also to other substances mixed within e-cigs ${ }^{122}$. Dry mouth, irritation, and throat symptoms are among frequently reported adverse effects of chronic usage of e-cigs. However, these adverse effects decrease with prolonged usage of e-cigs ${ }^{123}$. Most studies based these conclusions on self-report of dry mouth. To date, no publication has addressed objectively whole or glandular specific salivary hypofunction in e-cig users. E-cigs may transiently increase mucosal blood flow in the oral cavity. The clinical significance of this finding remains to be confirmed ${ }^{124}$. It certainly is true that nicotine in cigarettes may cause swelling and inflammation of the palatal minor salivary glands. Because levels of nicotine in e-cigs vary depending on the brand, adverse effects on minor salivary glands may be underreported. Further, hyposalivation is a significant risk factor for the development of oral fungal infections, which may be the underlying etiology for the reported prevalence of these lesions in both cigarette smokers and e-cig users.

\section{Type 2 Diabetes Mellitus (T2DM)}

While T2DM is clearly a general disease affecting many tissues across the body, it is clear that oral complications of this disease dramatically impact the 
overall health and quality of life of affected individuals. Exposure to nicotine in cigarettes and e-cigs affects endothelial function, promotes inflammation and oxidative stress, and increases the risk of developing glucose intolerance and T2DM ${ }^{125}$. Also, the bloodbrain barrier is affected, leading to cerebrovascular disease. Common medications for T2DM, metformin and rosiglitazone have shown in vitro upregulation of Nrf2, a related factor to the nuclear factor erythroid 2 and a potent antioxidant, anti-inflammatory that decreases endothelial damage ${ }^{125}$. The former medicine has been demonstrated in the same study to protect brain-blood barrier integrity. Albeit preliminary, this and other reports highlight potential in vivo implications for therapeutics targeting T2DM patients who also smoke or use e-cigs.

Another aldehyde, alpha-oxoaldehyde (MG), plays a major role in structural protein and receptor changes involved in the generation of advanced glycation end products (AGES), the main cytotoxic components of the diabetic process ${ }^{126}$. Modified MGIgG appears to be a potent oxidative and immune reactive molecule, potentially implicated in the cascade of glucose intolerance and overt T2DM. The fraction of this specific aldehyde in e-cigs is uncertain. However, there is ample evidence that T2DM patients are at a higher risk to develop cancer due to sustained hyperglycemia, while generation of AGEs via MG is implicated in the pathogenesis of renal, retinal and neuropathic complications in murine models of $\mathrm{T}_{2} \mathrm{DM}^{127}$. Further, generation of AGEs via MG may be responsible for the higher risk of cancer in these individuals ${ }^{127}$.

\section{CONCLUSION}

The past decade has seen a significant rise across the US in the use of e-cigs, especially among younger people. Recent studies have shown the presence of numerous potential carcinogens in e-cigs including nitrosamines and reactive carbonyls. Adducts from the heated flavoring components have been shown to have deleterious effects on host cells. Additionally, not only are the e-cigs an effective means for delivering high doses of nicotine but also may adversely affect oral health.

\section{REFERENCES}

1. Chaffee BW, Couch ET, Gansky SA. Trends in characteristics and multi-product use among adolescents who use electronic cigarettes, United States 2011-2015. PLoS One. 2017;12(5):e0177073. doi:10.1371/journal.pone.0177073

2. Cullen KA, Ambrose BK, Gentzke AS, Apelberg BJ, Jamal A, King BA. Notes from the Field: Use of Electronic Cigarettes and Any Tobacco Product Among Middle and High School Students - United States, 2011-2018. MMWR Morb Mortal Wkly Rep. 2018;67(45):1276-1277. doi:10.15585/mmwr.mm6745a5

3. American Academy of Pediatrics. Electronic Nicotine Delivery Systems: Section on Tobacco Control. Pediatrics. 2015;136(5):1018-1026. doi:10.1542/peds.2015-3222

4. Villanti AC, Johnson AL, Ambrose BK, et al. Flavored Tobacco Product Use in Youth and Adults: Findings From the First Wave of the PATH Study (2013-2014). Am J Prev Med. 2017;53(2):139-151. doi:10.1016/j.amepre.2017.01.026

5. Pentz MA, Shin H, Riggs N, Unger JB, Collison KL, Chou CP. Parent, peer, and executive function relationships to early adolescent e-cigarette use: a substance use pathway? Addict Behav. 2015;42:73-78. doi:10.1016/j.addbeh.2014.10.040

6. U.S. Department of Health and Human Services. E-Cigarette Use Among Youth and Young Adults. A Report of the Surgeon General. Atlanta, GA: U.S. Department of Health and Human Services, Centers for Disease Control and Prevention, National Center for Chronic Disease Prevention and Health Promotion, Office on Smoking and Health; 2016. https://e-cigarettes.surgeongeneral. gov/documents/2016_SGR_Full_Report_non-508.pdf. Accessed May, 2019.

7. Goniewicz ML, Knysak J, Gawron M, et al. Levels of selected carcinogens and toxicants in vapour from electronic cigarettes. Tob Control. 2014;23(2):133-139. doi:10.1136/tobaccocontrol-2012-050859

8. Sherry JS, Blackstad NM, Wheatley KS. E Cigarettes, Vaping and Chairside Education. https://www.rdhmag. com/home/article/16409913/e-cigarettes-vapingand-chairside-education. Published January 16, 2017. Accessed May, 2019.

9. Sundar IK, Javed F, Romanos GE, Rahman I. E-cigarettes and flavorings induce inflammatory and pro-senescence responses in oral epithelial cells and periodontal fibroblasts. Oncotarget. 2016;7(47):77196-77204. doi:10.18632/oncotarget.12857

10. Olmedo P, Goessler W, Tanda S, et al. Metal concentrations in e-cigarette liquid and aerosol samples: the contribution of metallic coils. Environ Health Perspect. 2018;126(2). doi:10.1289/EHP2175

11. Gaur S, Agnihotri R. Health Effects of Trace Metals in Electronic Cigarette Aerosols-a Systematic Review. Biol Trace Elem Res. 2018;188(2):295-315. doi:10.1007/s12011-018-1423-x

12. Zhao D, Navas-Acien A, Ilievski V, et al. Metal concentrations in electronic cigarette aerosol: Effect of open-system and closed-system devices and power settings. Environ Res. 2019;174:125-134. doi:10.1016/j.envres.2019.04.003 
13. Korzun T, Lazurko M, Munhenzva I, et al. E-Cigarette Airflow Rate Modulates Toxicant Profiles and Can Lead to Concerning Levels of Solvent Consumption. ACS Omega. 2018;3(1):30-36; doi:10.1021/acsomega.7b01521

14. Gillman IG, Kistler KA, Stewart EW, Paolantonio AR. Effect of variable power levels on the yield of total aerosol mass and formation of aldehydes in e-cigarette aerosols. Regul Toxicol Pharmacol. 2016;75:58-65. doi:10.1016/j.yrtph.2015.12.019

15. Sleiman M, Logue JM, Montesinos VN, et al. Emissions from Electronic Cigarettes: Key Parameters Affecting the Release of Harmful Chemicals. Environ Sci Technol. 2016;50(17):9644-9651. doi:10.1021/acs.est.6b01741

16. Talih S, Salman R, Karaoghlanian N, et al. 'Juice monsters': sub-ohm vaping and toxic volatile aldehyde emissions. Chem Res Toxicol. 2017;30(10):1791-1793. doi:10.1021/acs.chemrestox.7b00212

17. Kosmider L, Sobczak A, Fik M, et al. Carbonyl compounds in electronic cigarette vapors-effects of nicotine solvent and battery output voltage. Nicotine Tob Res. 2014;16(10):1319-1326. doi:10.1093/ntr/ntu078

18. Khlystov A, Samburova V. Flavoring compounds dominate toxic aldehyde production during e-cigarette vaping. Environ Sci Technol. 2016;50(23):13080-13085. doi:10.1021/acs.est.6b05145

19. Qu Y, Kim KH, Szulejko JE. The effect of flavor content in e-liquids on e-cigarette emissions of carbonyl compounds. Environ Res. 2018;166:324-333. doi:10.1016/j.envres.2018.06.013

20. Vreeke S, Peyton DH, Strongin RM. Triacetin Enhances Levels of Acrolein, Formaldehyde Hemiacetals, and Acetaldehyde in Electronic Cigarette Aerosols. ACS Omega. 2018;3(7):7165-7170. doi:10.1021/acsomega.8b00842

21. Saliba NA, El Hellani A, Honein E, et al. Surface chemistry of electronic cigarette electrical heating coils: Effects of metal type on propylene glycol thermal decomposition. J Anal Appl Pyrolysis. 2018;134:520-525. doi:10.1016/j.jaap.2018.07.019

22. Ogunwale MA, Li M, Ramakrishnam Raju MV, et al. Aldehyde Detection in Electronic Cigarette Aerosols. ACS Omega. 2017;2(3):1207-1214. doi:10.1021/acsomega.6b00489

23. Klager S, Vallarino J, MacNaughton P, Christiani DC, Lu Q, Allen JG. Flavoring chemicals and aldehydes in e-cigarette emissions. Environ Sci Technol. 2017;51(18):1080610813. doi:10.1021/acs.est.7b02205

24. Walele T, Bush J, Koch A, Savioz R, Martin C, O'Connell G. Evaluation of the safety profile of an electronic vapour product used for two years by smokers in a real-life setting. Regul Toxicol Pharmacol. 2018;92:226-238. doi:10.1016/j.yrtph.2017.12.010

25. Farsalinos KE, Voudris V, Poulas K. E-cigarettes generate high levels of aldehydes only in 'dry puff' conditions. Addiction. 2015;110(8):1352-1356. doi:10.1111/add.12942

26. Samburova V, Bhattarai C, Strickland M, et al.
Aldehydes in Exhaled Breath during E-Cigarette Vaping: Pilot Study Results. Toxics. 2018;6(3):46. doi:10.3390/toxics6030046

27. Bitzer ZT, Goel R, Reilly SM, et al. Effect of flavoring chemicals on free radical formation in electronic cigarette aerosols. Free Radic Biol Med. 2018;120:72-79. doi:10.1016/j.freeradbiomed.2018.03.020

28. Bishop E, Haswell L, Adamson J, Costigan S, Thorne D, Gaca M. An approach to testing undiluted e-cigarette aerosol in vitro using $3 \mathrm{D}$ reconstituted human airway epithelium. Toxicol In Vitro. 2019;54:391-401. doi:10.1016/j.tiv.2018.01.010

29. Son Y, Mishin V, Laskin JD, et al. Hydroxyl Radicals in E-cigarette Vapor and E-vapor Oxidative Potentials under Different Vaping Patterns. Chem Res Toxicol. 2019;12(11):13678-13695. doi:10.3390/ijerph121113678

30. Allen JG, Flanigan SS, LeBlanc M, et al. Flavoring chemicals in e-cigarettes: diacetyl, 2, 3-pentanedione, and acetoin in a sample of 51 products, including fruit-, candy-, and cocktail-flavored e-cigarettes. Environ Health Perspect. 2015;124(6):733-739. doi:10.1289/ehp.1510185

31. Hua M, Omaiye EE, Luo W, McWhirter KJ, Pankow JF, Talbot P. Identification of Cytotoxic Flavor Chemicals in Top-Selling Electronic Cigarette Refill Fluids. Sci Rep. 2019;9(1):2782. doi:10.1038/s41598-019-38978-w

32. Sherwood CL, Boitano S. Airway epithelial cell exposure to distinct e-cigarette liquid flavorings reveals toxicity thresholds and activation of CFTR by the chocolate flavoring 2, 5-dimethypyrazine. Respir Res. 2016;17(1):57. doi:10.1186/s12931-016-0369-9

33. Lerner CA, Sundar IK, Yao H, et al. Vapors produced by electronic cigarettes and e-juices with flavorings induce toxicity, oxidative stress, and inflammatory response in lung epithelial cells and in mouse lung. PloS One. 2015;10(2). doi:10.1371/journal.pone.0116732

34. Taylor M, Carr T, Oke O, et al. E-cigarette aerosols induce lower oxidative stress in vitro when compared to tobacco smoke. Toxicol Mech Methods. 2016;26(6):465-476. do i:10.1080/15376516.2016.1222473

35. Rouabhia M, Park HJ, Semlali A, Zakrzewski A, Chmielewski W, Chakir J. E-Cigarette Vapor Induces an Apoptotic Response in Human Gingival Epithelial Cells Through the Caspase-3 Pathway. J Cell Physiol. 2017;232(6):1539-1547. doi:10.1002/jcp.25677

36. Noël A, Verret CM, Hasan F, et al. Generation of Electronic Cigarette Aerosol by a Third-Generation Machine-Vaping Device: Application to Toxicological Studies. J Vis Exp. 2018;(138):e58095. doi:10.3791/58095

37. Kimbell J, Subramaniam R, Gross E, Schlosser P, Morgan K. Dosimetry modeling of inhaled formaldehyde: comparisons of local flux predictions in the rat, monkey, and human nasal passages. Toxicol Sci. 2001;64(1):100110. doi:10.1093/toxsci/64.1.111

38. Sultan AS, Jessri M, Farah CS. Electronic nicotine delivery systems: Oral health implications and oral cancer risk. J 
Oral Pathol Med. 2018. doi:10.1111/jop.12810

39. Weng MW, Lee HW, Park SH, et al. Aldehydes are the predominant forces inducing DNA damage and inhibiting DNA repair in tobacco smoke carcinogenesis. Proc Natl Acad Sci. 2018;115(27):E6152-E6161. doi:10.1073/pnas.1804869115

40. Ganapathy V, Manyanga J, Brame L, et al. Electronic cigarette aerosols suppress cellular antioxidant defenses and induce significant oxidative DNA damage. PLoS One. 2017;12(5):e0177780. doi:10.1371/journal.pone.0177780

41. Canistro D, Vivarelli F, Cirillo S, et al. E-cigarettes induce toxicological effects that can raise the cancer risk. Sci Rep. 2017;7(1):2028. doi:10.1038/s41598-017-02317-8

42. Pearson I, Taylor JL, Kingsley K. Evaluation of differential oral cell-specific responses to the E-cigarette component nicrotine. International Journal of Research and Reports in Dentistry. 2018;1(1):1-10.

43. Lei W, Lerner C, Sundar IK, Rahman I. Myofibroblast differentiation and its functional properties are inhibited by nicotine and e-cigarette via mitochondrial OXPHOS complex III. Sci Rep. 2017;7:43213. doi:10.1038/srep43213

44. Wadia R, Booth V, Yap HF, Moyes DL. A pilot study of the gingival response when smokers switch from smoking to vaping. Br Dent J. 2016;221(11):722-726. doi:10.1038/sj.bdj.2016.914

45. Zhang S, Zhang J, Chen H, et al. Combined cytotoxicity of co-exposure to aldehyde mixtures on human bronchial epithelial BEAS-2B cells. Environ Pollut. 2019;250:650661. doi:10.1016/j.envpol.2019.03.118

46. Rodriguez-Zavala JS, Calleja LF, Moreno-Sanchez R, Yoval-Sanchez B. Role of Aldehyde Dehydrogenases in Physiopathological Processes. Chem Res Toxicol. 2019;32(3):405-420. doi:10.1021/acs.chemrestox.8b00256

47. Chen Y, Liu Y, Hou X, Ye Z, Wang C. Quantitative and Site-Specific Chemoproteomic Profiling of Targets of Acrolein. Chem Res Toxicol. 2019;32(3):467-473. doi:10.1021/acs.chemrestox.8b00343

48. Park JH, Ku HJ, Park JW. Hesperetin mitigates acroleininduced apoptosis in lung cells in vitro and in vivo. Redox Rep. 2018;23(1):188-193. doi:10.1080/13510002.2018.1535640

49. Lin VY, Fain MD, Jackson PL, et al. Vaporized E-Cigarette Liquids Induce Ion Transport Dysfunction in Airway Epithelia. Am J Respir Cell Mol Biol. 2019:61(2). doi:10.1165/rcmb.2017-04320C

50. Clapp PW, Jaspers I. Electronic Cigarettes: Their Constituents and Potential Links to Asthma. Curr Allergy Asthma Rep. 2017;17(11):79. doi:10.1007/s11882-017-0747-5

51. Zhang S, Chen H, Wang A, Liu Y, Hou H, Hu Q. Combined effects of co-exposure to formaldehyde and acrolein mixtures on cytotoxicity and genotoxicity in vitro. Environ Sci Pollut Res Int. 2018;25(25):2530625314. doi:10.1007/s11356-018-2584-z

52. Zavala J, Ledbetter AD, Morgan DS, et al. A new cell culture exposure system for studying the toxicity of volatile chemicals at the air-liquid interface. Inhal Toxicol. 2018;30(4-5):169-

\section{7. doi:10.1080/08958378.2018.1483983}

53. Xiong R, Wu Q, Muskhelishvili L, et al. Evaluating Mode of Action of Acrolein Toxicity in an In Vitro Human Airway Tissue Model. Toxicol Sci. 2018;166(2):451-464. doi:10.1093/toxsci/kfy226

54. Colombo G, Dalle-Donne I, Orioli M, et al. Oxidative damage in human gingival fibroblasts exposed to cigarette smoke. Free Radic Biol Med. 2012;52(9):1584-1596. doi:10.1016/j.freeradbiomed.2012.02.030

55. Colombo G, Garavaglia ML, Astori E, et al. Protein carbonylation in human bronchial epithelial cells exposed to cigarette smoke extract. Cell Biol Toxicol. 2019. doi:10.1007/s10565-019-09460-0

56. Park HR, O'Sullivan M, Vallarino J, et al. Transcriptomic response of primary human airway epithelial cells to flavoring chemicals in electronic cigarettes. Sci Rep. 2019;9(1):1400. doi:10.1038/s41598-018-37913-9

57. Moses E, Wang T, Corbett S, et al. Molecular Impact of Electronic Cigarette Aerosol Exposure in Human Bronchial Epithelium. Toxicol Sci. 2017;155(1):248-257. doi:10.1093/toxsci/kfw198

58. de Groot PM, Wu CC, Carter BW, Munden RF. The epidemiology of lung cancer. Transl Lung Cancer Res. 2018;7(3):220-233. doi:10.21037/tlcr.2018.05.06

59. Kim BG, Lee PH, Lee SH, Hong J, Jang AS. Claudins, VEGF, Nrf2, Keap1, and Nonspecific Airway HyperReactivity Are Increased in Mice Co-Exposed to Allergen and Acrolein. Chem Res Toxicol. 2019;32(1):139-145. doi:10.1021/acs.chemrestox.8b00239

60. Kim SM, Hwang KA, Choi DW, Choi KC. The cigarette smoke components induced the cell proliferation and epithelial to mesenchymal transition via production of reactive oxygen species in endometrial adenocarcinoma cells. Food Chem Toxicol. 2018;121:657-665. doi:10.1016/j.fct.2018.09.023

61. Fuller TW, Acharya AP, Meyyappan T, et al. Comparison of Bladder Carcinogens in the Urine of E-cigarette Users Versus Non E-cigarette Using Controls. Sci Rep. 2018;8(1):507. doi:10.1038/s41598-017-19030-1

62. Ramoa CP, Eissenberg T, Sahingur SE. Increasing popularity of waterpipe tobacco smoking and electronic cigarette use: Implications for oral healthcare. J Periodontal Res. 2017;52(5):813-823. doi:10.1111/jre.12458

63. Bardellini E, Amadori F, Conti G, Majorana A. Oral mucosal lesions in electronic cigarettes consumers versus former smokers. Acta Odontol Scand. 2018;76(3):226228. doi:10.1080/00016357.2017.1406613

64. Sancilio S, Gallorini M, Cataldi A, di Giacomo V. Cytotoxicity and apoptosis induction by e-cigarette fluids in human gingival fibroblasts. Clin Oral Investig. 2016;20(3):477-483. doi:10.1007/s00784-015-1537-x

65. Welz C, Canis M, Schwenk-Zieger S, et al. Cytotoxic and Genotoxic Effects of Electronic Cigarette Liquids on Human Mucosal Tissue Cultures of the Oropharynx. J Environ Pathol Toxicol Oncol. 2016;35(4):343-354. 
doi:10.1615/JEnvironPatholToxicolOncol.2016016652

66. Rowell TR, Reeber SL, Lee SL, et al. Flavored e-cigarette liquids reduce proliferation and viability in the CALU3 airway epithelial cell line. Am J Physiol Lung Cell Mol Physiol. 2017;313(1):L52-L66. doi:10.1152/ajplung.00392.2016

67. Holliday R, Kist R, Bauld L. E-cigarette vapour is not inert and exposure can lead to cell damage. Evid Based Dent. 2016;17(1):2-3. doi:10.1038/sj.ebd.6401143

68. Ji EH, Sun B, Zhao T, et al. Characterization of Electronic Cigarette Aerosol and Its Induction of Oxidative Stress Response in Oral Keratinocytes. PLoS One. 2016;11(5):e0154447. doi:10.1371/journal.pone.0154447

69. Anderson C, Majeste A, Hanus J, Wang S. E-Cigarette Aerosol Exposure Induces Reactive Oxygen Species, DNA Damage, and Cell Death in Vascular Endothelial Cells. Toxicol Sci. 2016;154(2):332-340. doi:10.1093/toxsci/kfw166

70. Scott A, Lugg ST, Aldridge K, et al. Pro-inflammatory effects of e-cigarette vapour condensate on human alveolar macrophages. Thorax. 2018;73(12):1161-1169. doi:10.1136/thoraxjnl-2018-211663

71. Vasanthi Bathrinarayanan P, Brown JEP, Marshall LJ, Leslie LJ. An investigation into E-cigarette cytotoxicity in-vitro using a novel 3D differentiated co-culture model of human airways. Toxicol In Vitro. 2018;52:255-264. doi:10.1016/j.tiv.2018.06.020

72. Yanushevich OO, Ayvazova RA, Shibaeva AV, et al. Quantitative PGR studies of Aggregatibacter actinomycetemcomitans and Treponema denticola/ Tanerella forsythensis Complex as Etiological Factors of Chronic Periodontitis. Bull Exp Biol Med. 2016;160(4):495-497. doi:10.1007/s10517-016-3205-9

73. Feres M, Teles F, Teles R, Figueiredo LC, Faveri M. The subgingival periodontal microbiota of the aging mouth. Periodontol 2000. 2016;72(1):30-53. doi:10.1111/prd.12136

74. Zarco MF, Vess TJ, Ginsburg GS. The oral microbiome in health and disease and the potential impact on personalized dental medicine. Oral Dis. 2012;18(2):109120. doi:10.1111/j.1601-0825.2011.01851.x

75. Kriebel K, Hieke C, Muller-Hilke B, Nakata M, Kreikemeyer B. Oral Biofilms from Symbiotic to Pathogenic Interactions and Associated Disease -Connection of Periodontitis and Rheumatic Arthritis by Peptidylarginine Deiminase. Front Microbiol. 2018;9:53. doi:10.3389/fmicb.2018.00053

76. Docktor MJ, Paster BJ, Abramowicz S, et al. Alterations in diversity of the oral microbiome in pediatric inflammatory bowel disease. Inflamm Bowel Dis. 2012;18(5):935-942. doi:10.1002/ibd.21874

77. Kumar PS. Sex and the subgingival microbiome: do female sex steroids affect periodontal bacteria? Periodontol 2000. 2013;61(1):103-124. doi:10.1111/j.1600-0757.2011.00398.x

78. Reynolds MA. Modifiable risk factors in periodontitis: at the intersection of aging and disease. Periodontol 2000.
2014;64(1):7-19. doi:10.1111/prd.12047

79. Kilian M, Chapple IL, Hannig M, et al. The oral microbiome - an update for oral healthcare professionals. Br Dent J. 2016;221(10):657-666. doi:10.1038/sj.bdj.2016.865

80. Tatakis DN, Kumar PS. Etiology and pathogenesis of periodontal diseases. Dent Clin North Am. 2005;49(3):491-516. doi:10.1016/j.cden.2005.03.001

81. Socransky SS, Haffajee AD. Periodontal microbial ecology. Periodontol 2000. 2005;38:135-187. doi:10.1111/j.1600-0757.2005.00107.x

82. Benko S, Magyarics Z, Szabo A, Rajnavolgyi E. Dendritic cell subtypes as primary targets of vaccines: the emerging role and cross-talk of pattern recognition receptors. Biol Chem. 2008;389(5):469-485. doi:10.1515/bc.2008.054

83. Kumar H, Kawai T, Akira S. Pathogen recognition in the innate immune response. Biochem J. 2009;420(1):1-16. doi:10.1042/BJ20090272

84. Banchereau J, Briere F, Caux C, et al. Immunobiology of dendritic cells. Annu Rev Immunol. 2000;18:767-811. doi:10.1146/annurev.immunol.18.1.767

85. Javed F, Kellesarian SV, Sundar IK, Romanos GE, Rahman I. Recent updates on electronic cigarette aerosol and inhaled nicotine effects on periodontal and pulmonary tissues. Oral Dis. 2017;23(8):1052-1057. doi:10.1111/odi.12652

86. ALHarthi SS, BinShabaib M, Akram Z, Rahman I, Romanos GE, Javed F. Impact of cigarette smoking and vaping on the outcome of full-mouth ultrasonic scaling among patients with gingival inflammation: a prospective study. Clin Oral Investig. 2018. doi:10.1007/s00784-018-2725-2

87. Mokeem SA, Alasqah MN, Michelogiannakis D, Al-Kheraif AA, Romanos GE, Javed F. Clinical and radiographic periodontal status and whole salivary cotinine, IL-1beta and IL-6 levels in cigarette- and waterpipe-smokers and E-cig users. Environ Toxicol Pharmacol. 2018;61:38-43. doi:10.1016/j.etap.2018.05.016

88. Tatullo M, Gentile S, Paduano F, Santacroce L, Marrelli M. Crosstalk between oral and general health status in e-smokers. Medicine (Baltimore). 2016;95(49):e5589. doi:10.1097/MD.0000000000005589

89. Lacin N, Izol BS, Tuncer MC, Gokalp Ozkorkmaz E, Deveci B, Deveci E. Effects of formaldehyde on VEGF, MMP2, and Osteonectin levels in periodontal membrane and alveolar bone in the rats. Folia Morphol (Warsz). 2018. doi:10.5603/FM.a2018.0110

90. ArRejaie AS, Al-Aali KA, Alrabiah M, et al. Proinflammatory cytokine levels and peri-implant parameters among cigarette smokers, individuals vaping electronic cigarettes, and non-smokers. J Periodontol. 2018. doi:10.1002/JPER.18-0045

91. Sharab LY, Morford LA, Dempsey J, et al. Genetic and treatment-related risk factors associated with external apical root resorption (EARR) concurrent with orthodontia. Orthod Craniofac Res. 2015;18 Suppl 1:7182. doi:10.1111/ocr.12078 
92. Sodagar A, Donyavi Z, Arab S, Kharrazifard MJ. Effect of nicotine on orthodontic tooth movement in rats. Am J Orthod Dentofacial Orthop. 2011;139(3):e261-e265. doi:10.1016/j.ajodo.2010.08.018

93. Bakathir MA, Linjawi AI, Omar SS, Aboqura AB, Hassan AH. Effects of nicotine on bone during orthodontic tooth movement in male rats. Histological and immunohistochemical study. Saudi Med J. 2016;37(10):1127-1135. doi:10.15537/smj.2016.10.15159

94. Kirschneck C, Maurer M, Wolf M, Reicheneder C, Proff $P$. Regular nicotine intake increased tooth movement velocity, osteoclastogenesis and orthodontically induced dental root resorptions in a rat model. Int J Oral Sci. 2017;9(3):174-184. doi:10.1038/ijos.2017.34

95. Michelogiannakis D, Rossouw PE, Al-Shammery $\mathrm{D}$, et al. Influence of nicotine on orthodontic tooth movement: A systematic review of experimental studies in rats. Arch Oral Biol. 2018;93:66-73. doi:10.1016/j.archoralbio.2018.05.016

96. Kirschneck C, Proff P, Maurer M, Reicheneder C, Romer P. Orthodontic forces add to nicotine-induced loss of periodontal bone: An in vivo and in vitro study. J Orofac Orthop. 2015;76(3):195-212. doi:10.1007/s00056-015-0283-7

97. Naranjo AA, Trivino ML, Jaramillo A, Betancourth M, Botero JE. Changes in the subgingival microbiota and periodontal parameters before and 3 months after bracket placement. Am J Orthod Dentofacial Orthop. 2006;130(3):275.e17275.e22. doi:10.1016/j.ajodo.2005.10.022

98. Topaloglu-Ak A, Ertugrul F, Eden E, Ates M, Bulut H. Effect of orthodontic appliances on oral microbiota--6 month follow-up. J Clin Pediatr Dent. 2011;35(4):433436. doi:10.17796/jcpd.35.4.61114412637mt661

99. Bergamo AZN, Nelson-Filho P, Andrucioli MCD, do Nascimento C, Pedrazzi V, Matsumoto MAN. Microbial complexes levels in conventional and self-ligating brackets. Clin Oral Investig. 2017;21(4):1037-1046. doi:10.1007/s00784-016-1865-5

100.Torlakovic L, Paster BJ, Ogaard B, Olsen I. Changes in the supragingival microbiota surrounding brackets of upper central incisors during orthodontic treatment. Acta Odontol Scand. 2013;71(6):1547-1554. doi:10.3109/00016357.2013.776107

101.Sun F, Ahmed A, Wang L, Dong M, Niu W. Comparison of oral microbiota in orthodontic patients and healthy individuals. Microb Pathog. 2018;123:473-477. doi:10.1016/j.micpath.2018.08.011

102.Guo R, Zheng Y, Liu H, Li X, Jia L, Li W. Profiling of subgingival plaque biofilm microbiota in female adult patients with clear aligners: a three-month prospective study. Peer J. 2018;6:e4207. doi:10.7717/peerj.4207

103. Yanez-Vico RM, Iglesias-Linares A, Ballesta-Mudarra S, Ortiz-Ariza E, Solano-Reina E, Perea EJ. Short-term effect of removal of fixed orthodontic appliances on gingival health and subgingival microbiota: a prospective cohort study. Acta Odontol Scand. 2015;73(7):496-502. doi:10.3109/00016357.2014.993701

104.Tanner AC, Sonis AL, Lif Holgerson P, et al. White-spot lesions and gingivitis microbiotas in orthodontic patients. J Dent Res. 2012;91(9):853-858. doi:10.1177/0022034512455031

105.Klaus K, Eichenauer J, Sprenger R, Ruf S. Oral microbiota carriage in patients with multibracket appliance in relation to the quality of oral hygiene. Head Face Med. 2016;12(1):28. doi:10.1186/s13005-016-0125-x

106.Lucchese A, Bondemark L, Marcolina M, Manuelli M. Changes in oral microbiota due to orthodontic appliances: a systematic review. J Oral Microbiol. 2018;10(1):1476645. doi:10.1080/20002297.2018.1476645

107.Papageorgiou SN, Xavier GM, Cobourne MT, Eliades T. Effect of orthodontic treatment on the subgingival microbiota: A systematic review and metaanalysis. Orthod Craniofac Res. 2018;21(4):175-185. doi:10.1111/ocr.12237

108. Kim BS, Kim SJ, Kim HJ, et al. Effects of nicotine on proliferation and osteoblast differentiation in human alveolar bone marrow-derived mesenchymal stem cells. Life Sci. 2012;90(3-4):109-115. doi:10.1016/j.lfs.2011.10.019

109.Ma L, Zwahlen RA, Zheng LW, Sham MH. Influence of nicotine on the biological activity of rabbit osteoblasts. Clin Oral Implants Res. 2011;22(3):338-342. doi:10.1111/j.1600-0501.2010.02088.x

110. Marinucci L, Balloni S, Fettucciari K, Bodo M, Talesa VN, Antognelli C. Nicotine induces apoptosis in human osteoblasts via a novel mechanism driven by $\mathrm{H} 2 \mathrm{O} 2$ and entailing Glyoxalase 1-dependent MG-H1 accumulation leading to TG2-mediated NF-kB desensitization: Implication for smokers-related osteoporosis. Free Radic Biol Med. 2018;117:6-17. doi:10.1016/j.freeradbiomed.2018.01.017

111.Costa-Rodrigues J, Rocha I, Fernandes MH. Complex osteoclastogenic inductive effects of nicotine over hydroxyapatite. J Cell Physiol. 2018;233(2):1029-1040. doi:10.1002/jcp.25956

112.Li J, Wang X, Li N, Zhenga D, Su Y, Zhang J. Shortterm effects of nicotine on orthodontically induced root resorption in rats. Angle Orthod. 2016;86(2):199-205. doi:10.2319/101014-727.1

113.Otero CE, Noeker JA, Brown MM, et al. Electronic cigarette liquid exposure induces flavor-dependent osteotoxicity and increases expression of a key bone marker, collagen type I. J Appl Toxicol. 2019. doi:10.1002/jat.3777

114.Alanazi H, Semlali A, Chmielewski W, Rouabhia M. E-Cigarettes Increase Candida albicans Growth and Modulate its Interaction with Gingival Epithelial Cells. Int J Environ Res Public Health. 2019;16(2). doi:10.3390/ ijerph16020294

115. Wang G, Wang J, Ansari GAS, Khan MF. Autoimmune potential of perchloroethylene: Role of lipid-derived aldehydes. Toxicol Appl Pharmacol. 2017;333:76-83. doi:10.1016/j.taap.2017.08.009 
116.Cho JH. The association between electronic-cigarette use and self-reported oral symptoms including cracked or broken teeth and tongue and/or inside-cheek pain among adolescents: A cross-sectional study. PLoS One. 2017;12(7):e0180506. doi:10.1371/journal.pone.0180506

117.Jensen TK, Andersen MV, Nielsen KA, ArendtNielsen L, Boudreau SA. Interaction between intraoral cinnamaldehyde and nicotine assessed by psychophysical and physiological responses. Eur J Oral Sci. 2016;124(4):349-357. doi:10.1111/eos.12279

118.Hansen EO, Arendt-Nielsen L, Boudreau SA. A Comparison of Oral Sensory Effects of Three TRPA1 Agonists in Young Adult Smokers and Non-smokers. Front Physiol. 2017;8:663. doi:10.3389/fphys.2017.00663

119.Javed F, Abduljabbar T, Vohra F, Malmstrom H, Rahman I, Romanos GE. Comparison of Periodontal Parameters and Self-Perceived Oral Symptoms Among Cigarette Smokers, Individuals Vaping Electronic Cigarettes, and Never-Smokers. J Periodontol. 2017;88(10):1059-1065. doi:10.1902/jop.2017.170197

120.Gao J, Chen L, Zhou J, Peng J. A case-control study on etiological factors involved in patients with burning mouth syndrome. J Oral Pathol Med. 2009;38(1):24-28. doi:10.1111/j.1600-0714.2008.00708.x

121.Gualano MR, Passi S, Bert F, La Torre G, Scaioli G, Siliquini R. Electronic cigarettes: assessing the efficacy and the adverse effects through a systematic review of published studies. J Public Health (Oxf). 2015;37(3):488497. doi:10.1093/pubmed/fdu055

122.Pisinger C, Dossing M. A systematic review of health effects of electronic cigarettes. Prev Med. 2014;69:248260. doi:10.1016/j.ypmed.2014.10.009

123.Callahan-Lyon P. Electronic cigarettes: human health effects. Tob Control. 2014;23 Suppl 2:ii36-ii40. doi:10.1136/tobaccocontrol-2013-051470

124. Reuther WJ, Hale B, Matharu J, Blythe JN, Brennan PA. Do you mind if I vape? Immediate effects of electronic cigarettes on perfusion in buccal mucosal tissue--a pilot study. Br J Oral Maxillofac Surg. 2016;54(3):338-341. doi:10.1016/j.bjoms.2015.12.001

125. Sivandzade F, Cucullo L. Assessing the protective effect of rosiglitazone against electronic cigarette/tobacco smokeinduced blood-brain barrier impairment. BMC Neurosci. 2019;20(1):15. doi:10.1186/s12868-019-0497-5

126.Islam S, Moinuddin, Mir AR, Arfat MY, Alam K, Ali A. Studies on glycoxidatively modified human IgG: Implications in immuno-pathology of type 2 diabetes mellitus. Int J Biol Macromol. 2017;104(Pt A):19-29. doi:10.1016/j.ijbiomac.2017.05.190

127.Bellier J, Nokin MJ, Larde E, et al. Methylglyoxal, a potent inducer of AGEs, connects between diabetes and cancer. Diabetes Res Clin Pract. 2019;148:200-211. doi:10.1016/j.diabres.2019.01.002

128.Lamont RJ, Hajishengallis G. Polymicrobial synergy and dysbiosis in inflammatory disease. Trends Mol Med.
2015;21(3):172-183. doi:10.1016/j.molmed.2014.11.004

129.Mantovani A, Biswas SK, Galdiero MR, Sica A, Locati M. Macrophage plasticity and polarization in tissue repair and remodelling. J Pathol. 2013;229(2):176-185. doi:10.1002/path.4133

130.Hackstein H, Thomson AW. Dendritic cells: emerging pharmacological targets of immunosuppressive drugs. Nat Rev Immunol. 2004;4(1):24-34. doi:10.1038/nri1256

131.Sanmarco LM, Eberhardt N, Ponce NE, Cano RC, Bonacci G, Aoki MP. New Insights into the Immunobiology of Mononuclear Phagocytic Cells and Their Relevance to the Pathogenesis of Cardiovascular Diseases. Front Immunol. 2017;8:1921. doi:10.3389/fimmu.2017.01921

CONFLICTS OF INTEREST

The authors have completed and submitted the ICMJE Form for Disclosure of Potential Conflicts of Interest and none was reported.

\section{FUNDING}

There was no source of funding for this research.

\section{AUTHORS' CONTRIBUTIONS}

JE provided primary oversight to the organization of the review, as well as specific sections on periodontal disease. VS, AK and YS provided content for the toxic properties of e-cigs. DC, CD and AC provided the public health aspects of tobacco and e-cig use related to oral health. $\mathrm{KK}, \mathrm{KH}$ and NC provided review of cell biology effects of e-cigs. BC provided content on orthodontic aspects of e-cig use. AP provided the overview of research on general oral health conditions and e-cig use.

\section{PROVENANCE AND PEER REVIEW}

Not commissioned; externally peer reviewed. 